Report

\title{
Characterization of the estrogen receptor transfected MCF10A breast cell line 139B6
}

\author{
M.J. Pilat, ${ }^{1,3}$ J.K. Christman, ${ }^{2,4}$ and S.C. Brooks ${ }^{1}$ \\ ${ }^{1}$ Department of Biochemistry, Wayne State University School of Medicine, ${ }^{2}$ Molecular Oncology Program, \\ The Michigan Cancer Foundation Operating the Meyer L. Prentis Comprehensive Cancer Center, Metropolitan \\ Detroit, USA $;^{3}$ Present address: University of Michigan, Department of Internal Medicine, 1150 W. Medical \\ Center Drive, 5510 MSRBI, Ann Arbor, MI 48109-0680, USA; ${ }^{4}$ Present address: University of Nebraska, De- \\ partment of Biochemistry and Molecular Biology, 600 South 42nd Street, Omaha, NE 68798-4525, USA
}

Key words: $\beta$-actin promoter, breast cell lines, estradiol-17 $\beta$, estrogen receptor, MCF10A, transfection

\section{Summary}

There has been increasing evidence which suggests that abnormal expression of the estrogen receptor (ER) protein in nonmalignant breast tissue may be important in the carcinogenic process. To examine the effects of ER expression in immortalized nonmalignant mammary epithelial cells, an expression vector containing human ER cDNA was transfected into the ER negative human breast cells, MCF10A. Characterization of a clone stably expressing ER, 139B6, provided evidence for the regulated synthesis of a functional ER capable of binding estradiol-17 $\beta\left(\mathrm{E}_{2}\right)$ and undergoing processing. Expression of the ER gene did not enable $\mathrm{E}_{2}$ to stimulate endogenous genes [progesterone receptor (PgR), pS2, cathepsin D and TGF $\alpha$ ] which normally respond to estrogens in breast cancer cells. The ER in 139B6 cells was, however, capable of inducing expression of an ERE-regulated reporter gene, indicating its ability to interact with transcriptional machinery. Furthermore, cultures in log growth displayed a slight increase in doubling time in the presence of $\mathrm{E}_{2}$. These results indicate that ER expression alone is not sufficient to induce a transformed phenotype. Thus, the 139B6 cell line should provide a new model for determining what additional changes lead to increased growth potential in response to $\mathrm{E}_{2}$ and for exploring how $\mathrm{E}_{2}$ itself may help bring about changes leading to progression of preneoplastic breast epithelial cells.

\section{Introduction}

Although it has not been possible to determine the direct role of estradiol-17 $\beta\left(\mathrm{E}_{2}\right)$ in breast cancer, excessive estrogen exposure has been implicated in the induction of breast cancer for over 100 years [1]. $E_{2}$, which exerts its effects by binding to an intracellular receptor to induce estrogen responsive genes, is thought to be mitogenic for both breast tumors and normal breast tissue. However, the regulation of growth by this hormone differs. In normal breast, $\mathrm{E}_{2}$ exerts its effects in a carefully regulated manner, as opposed to the uncontrolled growth observed in $\mathrm{E}_{2}$-dependent breast cancer cells [2]. Expression of the estrogen receptor (ER) in normal breast also differs from that observed in breast tumors. Under nonlactating conditions, normal breast does not express ER in abundance. Roughly $7 \%$ of the total ep- 
ithelial cell population of breast tissue biopsies contain ER, while approximately $75 \%$ of breast tumor biopsies express significant levels of ER [3, 4]. Furthermore, a recent study by Khan et al. found a strong association between ER positivity of benign breast epithelium and breast cancer risk [5]. These observations imply that ER itself may be important in the carcinogenic process.

It has long been believed that development of cancer is a multistep process, arising from the accumulation of multiple genetic and epigenetic alterations $[6,7]$. The properties of breast cancer cells in culture have been well studied as a number of breast epithelial tumor cell lines (MCF-7, ZR-75, and T47D) have been established. Primary cultures of normal breast epithelium have proven more difficult to study long term, as these cultures eventually undergo senescence. Established normal immortalized breast epithelial cell lines are rare and have been difficult to establish without chemical or viral intervention [8-15]. The recent development of the spontaneously immortalized MCF10 cell lines by Soule and coworkers [9] has thus provided a unique model system in which to examine the progression between immortalization and transformation of breast epithelial cells.

The MCF10 lines arose spontaneously from mortal cells cultured from breast tissue of a woman with fibrocystic disease. Several of these lines (MCF10A, $10 \mathrm{~F}$, etc.) have survived in culture for more than 7 years [9]. The MCF10A cell line is pseudodiploid with minimal chromosomal rearrangements and exhibits many of the properties of a nonmalignant cell line, including the inability to induce tumors in athymic mice, even in the presence of estrogen [9]. Most important for this study, MCF10A cells, like most normal breast epithelial cells, do not express ER mRNA or protein despite having an apparently unaltered gene [ 9 ; see below].

The results of previous studies investigating the introduction of ER into cell lines have been varied. The transient expression of a functional ER has been demonstrated after transfection of yeast, $\mathrm{He}$ La cells and chicken embryo fibroblasts [16-18]. Stable expression of transfected ER genes has also been obtained in a number of cultures including the Chinese hamster ovary (CHO) [19], HeLa [20], Syr- ian hamster uterine myocyte [21], and osteosarcoma ROS17/2.8 cell lines [22]. ER genes have also been transfected into both immortal (184B5) and ER negative tumorigenic (21MT-2 and MDAMB-231) breast cell lines [2, 23, 24]. These studies indicate that expression of functional ER in transfected breast cell lines leads to stimulation of some $E_{2}$ regulated genes upon exposure to $E_{2}$. Rather than being stimulatory, however, cell proliferation is inhibited when cultures are exposed to $E_{2}[2,23]$. In an effort to better understand the role of $E_{2}$ and ER in the early stages of breast cancer development, we have selected and studied MCF10A cells stably expressing ER after transfection with a mammalian expression vector containing ER cDNA.

\section{Materials and methods}

\section{Cell culture}

The MCF10A1 cell line (obtained from Dr. Jose Russo, Fox Chase Cancer Center, Philadelphia, PA), as well as all transfectants, were maintained in optimal growth media: a phenol red- and HEPESfree custom formulation of DMEM: F12 media (1:1; Gibco, Gaithersburg, MD; formula number 905149-EG) supplemented with $1.05 \mathrm{mM}$ calcium chloride (Sigma, St. Louis, MO), $5 \%$ equine serum (Gibco), cholera enterotoxin (100 ng/ml; ICN Biomedicals, Cleveland, $\mathrm{OH})$, insulin $(10 \mu \mathrm{g} / \mathrm{ml}$; Sigma), cortisol $\left(1.4 \times 10^{-6} \mathrm{M}\right.$; Sigma $)$, epidermal growth factor (EGF; $20 \mathrm{ng} / \mathrm{ml}$; Gibco), and antibiotics (penicillin, $100 \mathrm{U} / \mathrm{ml}$; streptomycin, $100 \mu \mathrm{g} /$ $\mathrm{ml}$; amphotericin, $0.25 \mu \mathrm{g} / \mathrm{ml}$, and gentamicin sulfate, $0.5 \mu \mathrm{g} / \mathrm{ml}$; all from Sigma). For experiments, cultures were exposed to $10^{-8} \mathrm{M} \mathrm{E}_{2}$ (in ethanol) for the indicated times in media containing dextran coated charcoal (DCC) stripped serum (to minimize $E_{2}$ content; 25) while control cells received ethanol vehicle in this medium.

\section{Construction of pH $\beta$-Apr-1-neo-ER $R_{w t}$ (Fig. 1)}

Wildtype ER cDNA (ER ${ }_{w}$; a gift of P. Chambon 26) was subcloned into the BamHI site of the $\mathrm{pH} \beta$ - 


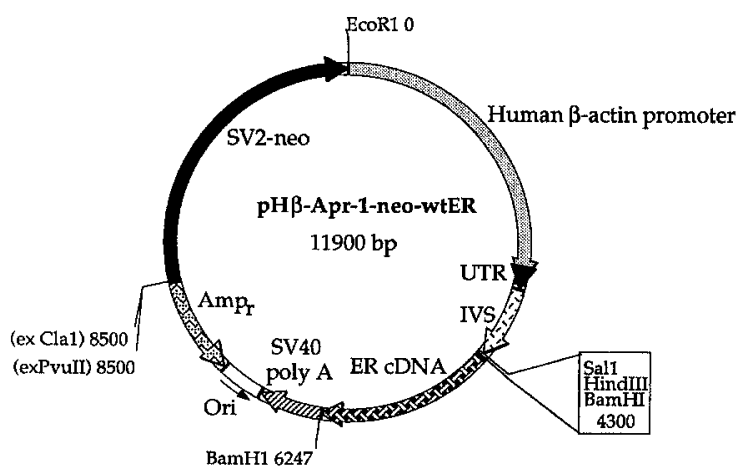

Fig. 1. The expression vector $\mathrm{pH} \beta-\mathrm{Apr} 1-\mathrm{neo}-\mathrm{ER}_{\mathrm{wr}}$. The $1.9 \mathrm{~kb}$ EcoRI ER cDNA fragment [26] was inserted into the BamHI polylinker site of the $\mathrm{pH} \beta$-Apr1-neo vector. This vector contains $3 \mathrm{~kb}$ of the human $\beta$-actin $5^{\prime}$ flanking sequence plus $78 \mathrm{bp}$ of $5^{\prime}$ untranslated region (UTR), $832 \mathrm{bp}$ of intervening sequence 1 (IVS1), SV40 polyadenylation signal (SV40 poly A), and the resistant genes for ampicillin (Amp $)$ and neomycin (SV2-neo; 27).

Apr-1-neo vector (a gift of T. Trevor 27). Briefly, the $1.9 \mathrm{~kb}$ EcoRI ER cDNA fragment (cloned into the EcoRI site of the pSG5 vector; 26,28) was ligated to EcoRI-BamHI adaptors (synthesized by Biosynthesis, Inc., Denton, TX). Unreacted adaptors were separated on a Sepharose CL-4B (Sigma) column and the insert was subcloned into the BamHI site of the pH $\beta$-Apr-1-neo vector $[29,30]$.

\section{Transfection of MCF10A cells $p H \beta-A p r-1-n e o-E R_{w t}$}

$\mathrm{pH} \beta$-Apr-1-neo-ER $\mathrm{wt}_{\mathrm{wt}}$ was transfected into MCF-10A cells using a modified version of the calcium phosphate mediated transfection procedure [29]. This mammalian expression vector contains $3 \mathrm{~kb}$ of the human $\beta$-actin $5^{\prime}$ flanking sequence along with the genes for ampicillin ( $\beta$-lactamase) and neomycin (aminoglycoside phosphotransferase) resistance [27]. Ten $\mu \mathrm{g}$ of plasmid DNA were used per $60 \mathrm{~mm}$ culture dish of cells (roughly $60 \%$ confluent) and the $\mathrm{pH}$ of this transfection solution was adjusted to 7.0, a critical step for optimum transfection efficiency. Calcium chloride ( $2 \mathrm{M}$ ) was added slowly to the mixture (final concentration of $125 \mathrm{mM}$ ) and allowed to precipitate for 30 minutes at room temperature prior to addition to the cells. The mixture was allowed to incubate on the cells for 5 hours at $37^{\circ} \mathrm{C}$ in a humidified $5 \% \mathrm{CO}_{2}$ incubator.
The medium was then removed, the cells washed once with phosphate buffered saline (PBS), and the cells glycerol-shocked with $20 \%$ glycerol for $4 \mathrm{~min}$ utes to increase the efficiency of transfection. The cells were rinsed twice with PBS and allowed to grow in complete medium for 72 hours. The selective agent, Geneticin (G418 Sulfate; Gibco) was then added at a concentration of $300 \mu \mathrm{g} / \mathrm{ml}$ of media and cells grown for at least 3 weeks before individual clones were chosen.

\section{Northern analysis}

PolyA mRNA was extracted, separated by agarose gel electrophoresis, and transferred to Nytran membranes (Schleicher and Schuell, Keene, NH) according to previously published procedures [31, 32]. Membranes were probed with the following ${ }^{35} \mathrm{~S}$ radiolabeled cDNAs: ER (HEGO; a gift of P. Chambon); cathepsin D (pNR100; a gift from B. Westley); pS2 (a gift from P. Chambon); TGF- $\alpha$ (sp65C17N3; a gift of R. Derynck); and progesterone receptor (PgR; pGR7ZF/EBR14A-1 kb of the bovine steroid binding domain, a gift of $\mathrm{D}$. Skafar). Membranes were subsequently probed with ${ }^{35} \mathrm{~S}$ radiolabeled 36B4 (a gift of P. Chambon) or human $\alpha$-tubulin (gift of $T$. Trevor) to evaluate integrity of mRNAs and to provide an internal reference for variations in the amount of RNA loaded in each lane. Hybridization and membrane washing were carried out according to previously published procedures [32]. For each experiment, approximately $2.0 \times 10^{7} \mathrm{cpms}$ of the probe (specific activity of approximately $10^{9} \mathrm{cpm} / \mu \mathrm{g}$ ) were added to the hybridization buffer after denaturation at $95^{\circ} \mathrm{C}$ for 10 minutes. Results were quantitated with a Molecular Dynamics densitometer employing Imagequant ${ }^{\mathrm{TM}}$ software (Sunnyvale, CA).

\section{Immunochemical detection of ER}

Cells were plated in 8 well tissue culture chamber slides (Nunc, Inc., Naperville, IL) at approximately 50,000 cells per well and grown to $50 \%$ confluency (roughly 100,000 cells per well) in a $37^{\circ} \mathrm{C}$ humid- 
ified $\mathrm{CO}_{2}$ environment. Immunocytochemical detection of ER was performed using the Abbott ERICA Monoclonal Kit (Abbott Park, IL) following procedure outlined by the manufacturer. The presence of ER was detected using diaminobenzidine-4 $\mathrm{HCl}$ as a substrate. Only cells with a darkly stained (brown) nucleus were considered positive for ER. Staining of transfectant cell lines was compared to that obtained with MCF-7 cells, which express high levels of ER.

\section{Determination of levels of ER}

The levels of ER were measured both by ligand binding and by enzyme immunoassay methods. For ligand binding, the classic dextran coated charcoal binding assay developed by Davies et al. [33] was used. All experiments were carried out at $4^{\circ} \mathrm{C}$. Cells were grown to approximately $60 \%$ confluency $\left(1 \times 10^{7}\right.$ cells $)$ in $75 \mathrm{~cm}^{2}$ flasks. Cells from 4 flasks were suspended in $4.5 \mathrm{ml}$ ice cold TE buffer $\mathrm{pH} 7.5$ plus $1 \mathrm{mM}$ dithiothreitol (DTT), transferred to a dounce homogenizer, and homogenized with 15 strokes of a glass pestle on ice. The homogenate was then centrifuged at $100,000 \mathrm{~g}$ for 60 minutes at $4^{\circ} \mathrm{C}$. The pellets were stored at $-20^{\circ} \mathrm{C}$ for DNA quantitation. Aliquots of cytosolic extract $(0.4 \mathrm{ml})$ were incubated with tritiated $\mathrm{E}_{2}\left(2,4,6-{ }^{3} \mathrm{H}\right)-\mathrm{E}_{2}, 96 \mathrm{Ci} /$ mmol, NEN DuPont, Boston, MA] over a concentration range of $0.2-1.77 \mathrm{nM}$ with and without a 200 fold excess of unlabeled $\mathrm{E}_{2}$. This mixture was allowed to incubate overnight at $4^{\circ} \mathrm{C}$. Dextran coated charcoal solution $(0.4 \mathrm{ml}-\mathrm{DCC} ; 0.5 \%$ charcoal, $0.003 \mathrm{mM}$ dextran, $1 \mathrm{mM}$ DTT in $1 \times \mathrm{TE} \mathrm{pH} \mathrm{7.4)}$ was added to each sample, the tubes mixed and incubated on ice for 15 minutes. Upon centrifugation at $2000 \mathrm{~g}$ for 15 minutes, aliquots $(250 \mu \mathrm{l})$ of each sample were added to $2 \mathrm{ml}$ ethanol and $10 \mathrm{ml}$ scintillation fluid (Scintiverse E; Fisher Scientific, Pittsburg, PA), and the radioactivity determined in a Packard Tricarb 4530 scintillation counter. Mathematical treatment of the results were patterned after Davies [33] and Scatchard [34].

For the enzyme immunoassay, cells were grown to $50 \%$ confluence in $75 \mathrm{~cm}^{2}$ flasks; $10^{-8} \mathrm{M} \mathrm{E}_{2}$ was added for 0 (ethanol vehicle), 1, 3, 6 or 24 hours.
Cells were harvested and cytosolic and nuclear extracts were prepared as previously described [35, 36]. ER content was measured in both nuclear and cytosolic extracts following protocols previously described [35].

\section{Quantitation of DNA}

The amount of DNA in each of the pellets described above was measured by a modified method of Burton [37] as previously described [35].

\section{Growth curves}

MCF10 cells and their derivatives were seeded at densities of $3 \times 10^{4}$ to $1 \times 10^{5}$ in $25 \mathrm{~cm}^{2}$ culture flasks containing experimental medium (optimal growth medium minus EGF, insulin, cortisol, and cholera enterotoxin) supplemented with $5 \%$ equine serum and antibiotics. Sufficient flasks were prepared to provide three measurements of cell number at each time point during indicated treatments. One day later, the medium was changed on alternate days until cells approached confluence, at which point the media was changed daily.

Growth of cultures was monitored utilizing the procedures described by Weise et al. [25]. Briefly, cells were allowed to swell in a hypotonic HEPES buffer $\left(2 \mathrm{ml} / 25 \mathrm{~cm}^{2}\right.$; $0.01 \mathrm{M}$ HEPES, $0.015 \mathrm{M}$ magnesium chloride) for 10 minutes at room temperature. The cells were then lysed by incubating with detergent [200 $\mu \mathrm{l} / \mathrm{T} 25$ of 0.13 ethylhexadecyldimethylammonium bromide (Eastman Kodak, Rochester, NY) in 3\% v/v of acetic acid (Fisher)]. The resulting nuclear suspension was diluted to appropriate volumes with filtered saline and counted with a Coulter Counter [38]. Cell number was determined at a minimum of 9 time points to establish a growth curve.

Transfection of the 139B6 and 139-2-8 cell lines for transient $C A T$ expression assays

Eighteen to twenty-four hours prior to transfection, 


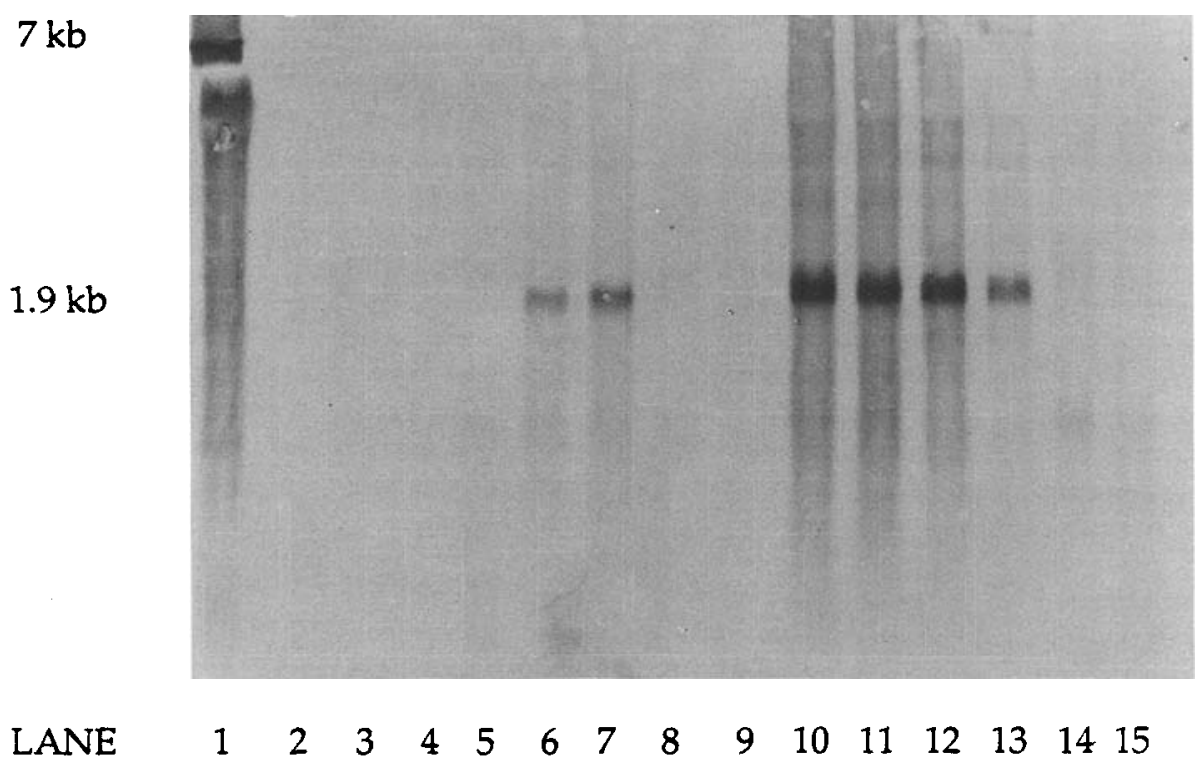

Fig. 2. Representative Northern blot of mRNA from selected clones of the MCF10A cell line transfected with pH $\beta$-Apr-1-neo-ER probed with radiolabeled ${ }^{35} \mathrm{~S}$ ER cDNA. Blots were subsequently washed and reprobed with ${ }^{35} \mathrm{~S}$ radiolabeled $\alpha$-tubulin cDNA to control for variations in RNA loading. Lane 1 represents mRNA extracted from the human breast cancer cell line, MCF-7. Note the expected $7 \mathrm{~kb}$ endogenous ER mRNA. Lanes 2 and 3 represent mRNAs extracted from parental MCF10A cells. Lanes 4 and 5 represent mRNAs from a pH $\beta$-Apr1-neo vector transfected MCF10A cell line, 139-2-8. Lanes 6 through 15 represent mRNAs extracted from pH $\beta$-Apr1-neo-ER ${ }_{w t}$ transfected MCF10A cell lines. Positive clones expressed ER mRNA of $1.9 \mathrm{~kb}$. Lanes 12 and 13 represent mRNA extracted from 139B6 cultures.

cells were plated at $1 \times 10^{6}$ cells per $60 \mathrm{~mm}$ tissue culture dish. Three hours prior to transfection, the medium was replaced with DMEM/F12 medium adjusted to $\mathrm{pH}$ 7.3-7.4. Cultures were transfected with an ER-responsive CAT reporter gene using the strontium phosphate procedure described by Brash et al. [39] modified by incubating the cells with $10 \mu \mathrm{g}$ of DNA (JA12 plasmid [40]) per dish for 4 hours followed by a 4 minute incubation with $20 \%$ glycerol. The cells were then treated with $10^{-8} \mathrm{M} \mathrm{E}_{2}$, $10^{-7} \mathrm{M}$ ICI 164,384 , or ethanol vehicle for $48-72$ hours. Separate cultures were also transfected with RSV-CAT to monitor transfection efficiency [40].

\section{CAT assays}

CAT assays were carried out as described by Gorman [41]. Predetermined amounts of supernatant protein from each sample $(5 \mu \mathrm{g}$ for the $139 \mathrm{~B} 6$ cell line and $75 \mu \mathrm{g}$ for the 139-2-8 control line) were added to reaction mixtures with $0.1 \mu \mathrm{Ci}$ of ${ }^{14} \mathrm{C}$-chloram- phenicol (40-60 $\mathrm{mCi} / \mathrm{mmol}$; ICN radiochemicals, Irvine, CA). The reaction was incubated for 2 hours at $37^{\circ} \mathrm{C}$. Acetylated chloramphenicol was separated by thin-layer chromatography and visualized by autoradiography. Spots were excised and radiolabel quantitated by liquid scintillation counting. Protein concentrations were determined utilizing the Pierce BSA assay kit (Rockford, IL).

\section{Results}

pHß-Apr-1-neo-ER $\mathrm{wt}_{\mathrm{wt}}$ was transfected into the MCF10A cell line. The parent vector (pH $\beta$-Apr-1neo) was also transfected into MCF10A cells to serve as a control. After 3 weeks exposure to $300 \mu \mathrm{g} / \mathrm{ml}$ Geneticin, $10-15$ resistant clones from each transfection were isolated and expanded.

mRNA was extracted from randomly selected Geneticin resistant clones and tested for expression of ER mRNA. A representative Northern blot of mRNAs from several clones is shown in Fig. 2. Ap- 

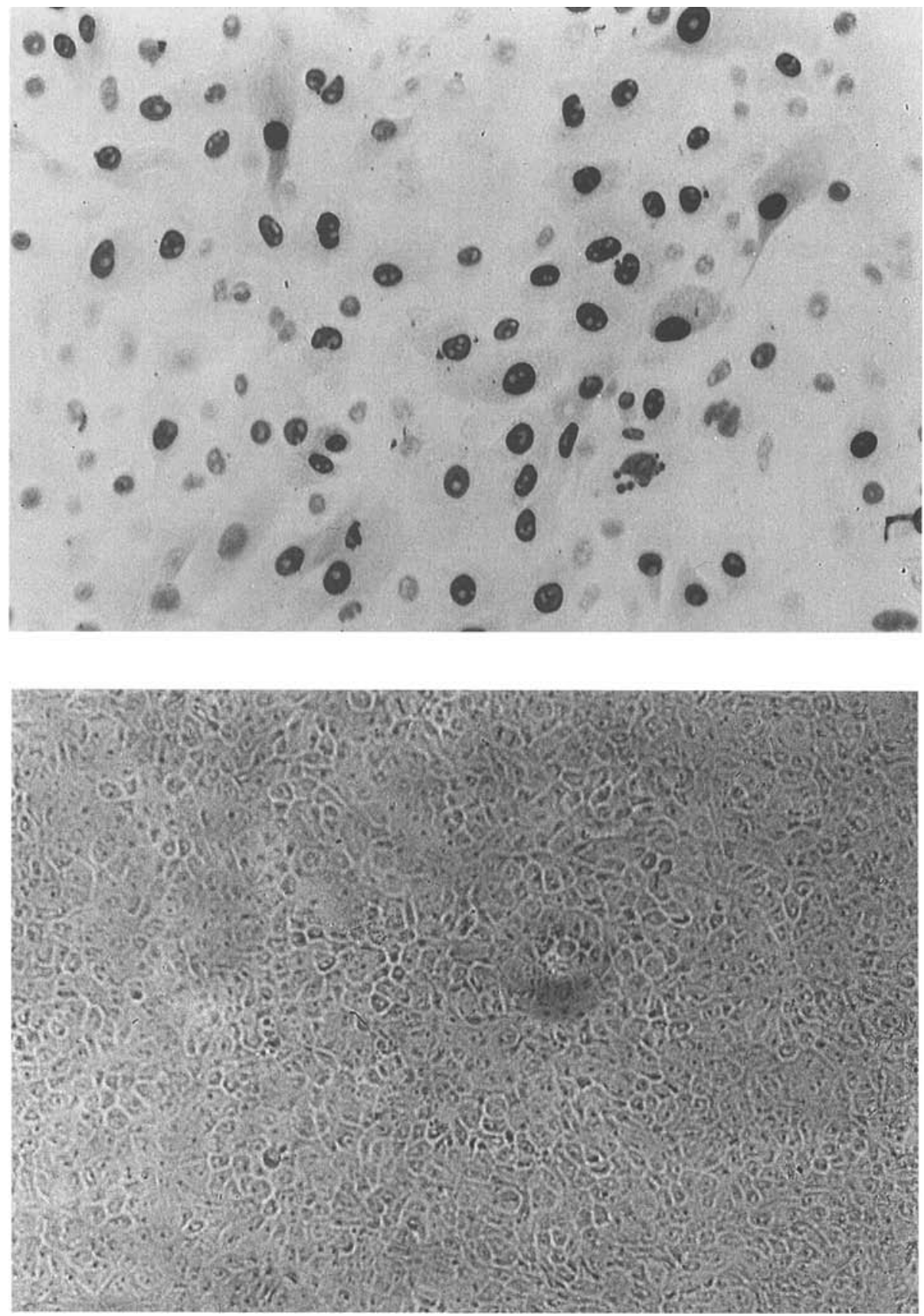

extracted from these clones also indicated the presence of the expected $1.9 \mathrm{~kb}$ fragment upon digestion with either BamHI or EcoRI. This fragment was not detected in the parental MCF10A cell line or MCF10A cells transfected with the control plasmid (data not shown).

Several clones from each transfection were testER mRNA. Restriction analysis of genomic DNA 


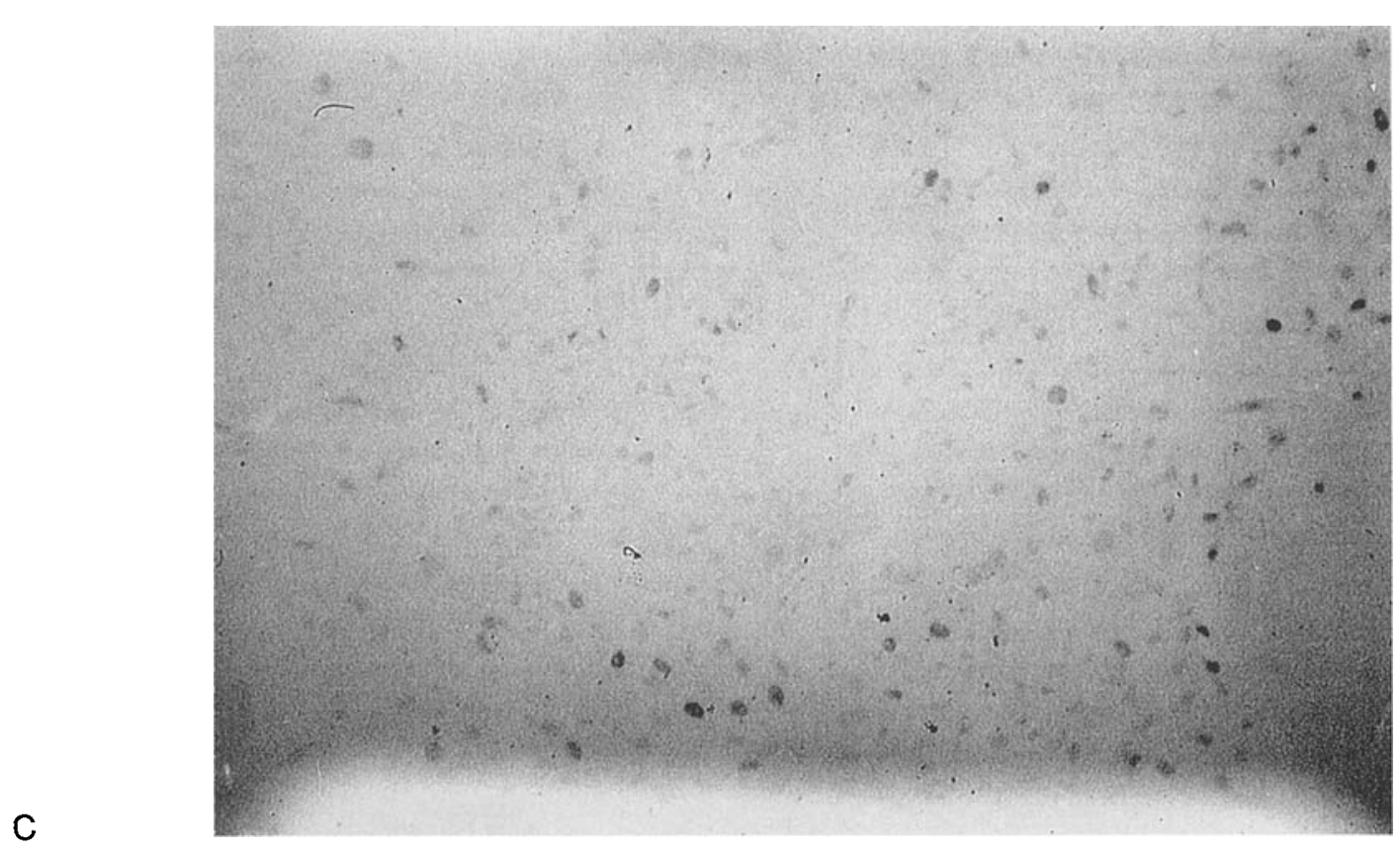

Fig. 3. Immunocytochemical detection of ER protein in 139B6 and 139-2-8 cell lines. Cultures were stained for ER protein using Abbott's ER-ICA kit. Darkly stained nuclei indicate the presence of ER. Cells were photographed using a phase contrast microscope. A) Subconfluent 139B6 cultures. B) 139-2-8 cultures. C) Postconfluent 139B6 cultures.

ed for expression of ER protein. MCF-7 cells, which express high levels of ER, were used as a positive control and the parent MCF10A cells were used as a negative control. ER positive cells displayed an intense nuclear staining (Fig. 3a). Cells transfected with the parent vector alone (line 139-2-8) did not express ER (Fig. 3b). Faint background staining throughout the cell was common to all cells examined. One clone, 139B6, which expressed ER abundantly (70-90\% of the cells) was selected for study. Further immunocytochemical analysis of the 139B6 cell line revealed a loss of ER expression when cells reached confluence (Fig. 3c). More than $80 \%$ of cells expressed abundant ER until the density of the cultures reached approximately $80 \%$ confluence. After this point, both the proportion of ER positive cells and the intensity of nuclear staining decreased dramatically (Fig. 3c). Thus, it appears these cells only express ER during log phase growth. Analysis of both the parent MCF10A and the control 139-2-8 cell lines failed to detect ER expression at any level of confluence examined (Fig. 3b; data not shown). All subsequent experiments were performed on subconfluent cultures to ensure expression of ER.
Western analysis of nuclear lysates from the 139B6 cell line detected the presence of anti-ER reactive protein of approximately $67 \mathrm{kD}$, the expected molecular weight for ER (data not shown).

The levels of ER in the 139B6 cell line were measured both by ligand binding and by enzyme immunoassay methods. Cytosolic extracts of cultures were analyzed for their ER content by the classical DCC binding assay. Figure 4 depicts saturation curves obtained for each of these cell lines at $4^{\circ} \mathrm{C}$. Both the MCF-7 (Fig. 4a) and 139B6 (Fig. 4c) cells contained significant levels of $\mathrm{ER}$, whereas cytosolic extracts of the parent MCF10A (Fig. 4b) and vector transfected 139-2-8 (Fig. 4d) cells contained no ER detectable by this assay. Scatchard analysis yielded a dissociation constant of $1.51 \times 10^{-10} \mathrm{M}$ for the ER expressed in the 139B6 cells, comparable to that obtained for the ER in MCF-7 cells $(1.41 \times$ $10^{-10} \mathrm{M}$; data not shown). ER levels were also comparable for the two cell lines, yielding 1.24 fmoles $\mathrm{ER} / \mu \mathrm{g}$ of DNA for the 139B6 cell line and $0.8 \mathrm{fmoles} \mathrm{ER} / \mu \mathrm{g}$ of DNA for MCF-7 cells (average range is $1-4$ fmoles ER/ $\mu$ g of DNA for MCF-7 cells; L. Polin, unpublished results; data not shown). 

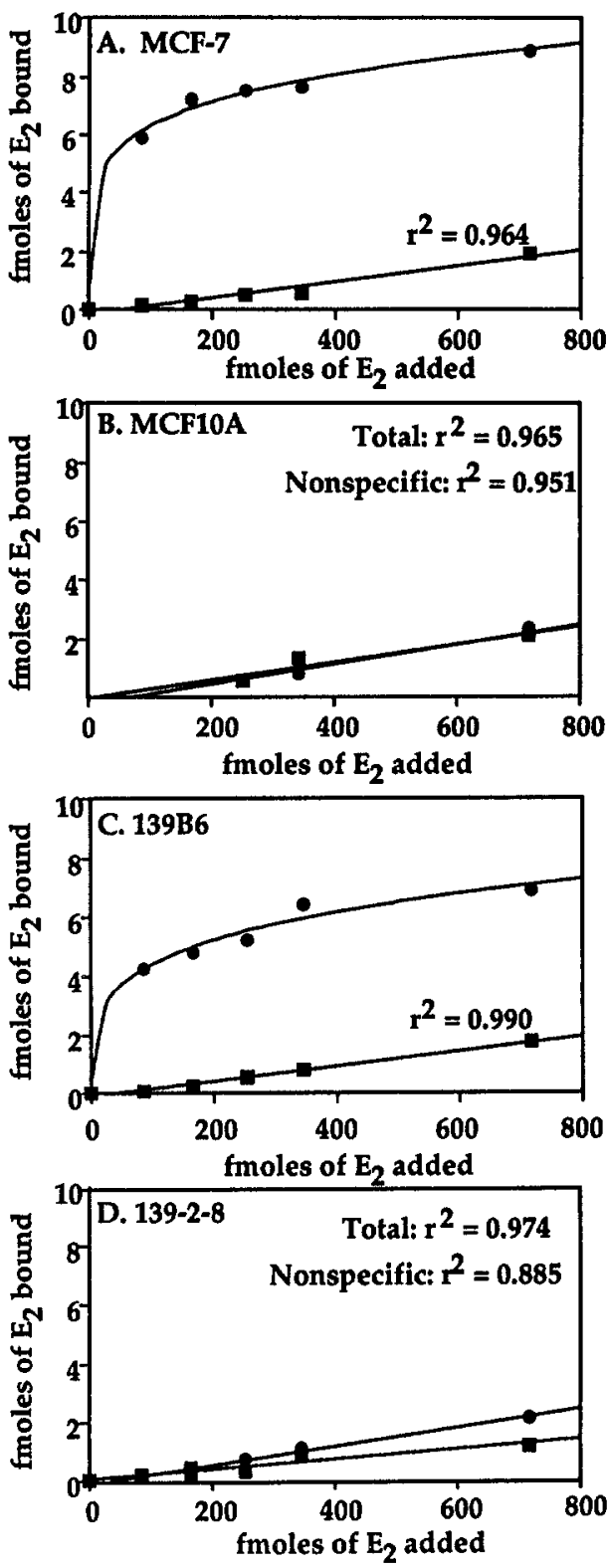

Fig. 4. Detection of $\mathrm{E}_{2}$ binding sites in cytosolic extracts of MCF-7, MCF10A, and transfected MCF10A cells. Saturation binding data of ${ }^{3} \mathrm{HE}_{2}$ binding to cytosolic extract of: $\mathrm{A}$ ) the positive control MCF-7; B) the parent cell line MCF10A; C) the ER transfected MCF10A clone 139B6; and D) the mock transfected MCF10A clone 139-2-8. Cytosolic extracts from MCF-7, MCF10A, 139B6, and 139-2-8 cells were incubated for 24 hours at $4^{\circ} \mathrm{C}$ with a range of ${ }^{3} \mathrm{H} \mathrm{E}_{2}$ concentrations in the presence (nonspecific binding depicted by $\mathbf{\square}$ ) and absence (total binding depicted by $)$ ) of unlabeled $E_{2}$ utilizing procedures described in Materials and methods. Specific binding was calculated as the difference between total and nonspecific binding. These values were used for Scatchard analysis (data not shown).

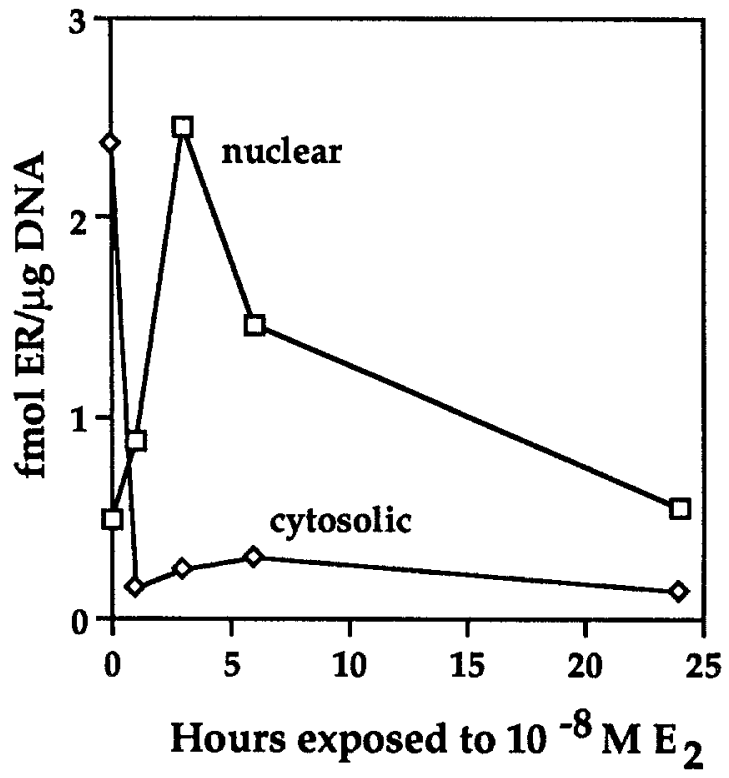

Fig. 5. Nuclear binding of the ER complex in the 139B6 cell line. Subconfluent cultures were pulsed with $10^{-8} \mathrm{ME}_{2}$ for $0,1,3,6$ and 24 hours prior to harvesting. Cytosolic $(\diamond)$ and nuclear $(\square)$ extracts were prepared from separate flasks utilizing the procedures described in Materials and methods. ER levels were detected with monoclonal antibodies using Abbott's ER-EIA kit. Points indicate the average of two determinations. Experimental results were compared to results with extracts from the ER containing MCF-7 cell line (data not shown).

Levels of ER were also measured by ER-enzyme immunoassay (ER-EIA). Exposure of subconfluent cultures of 139B6 cells to $E_{2}$ brought about classic tight nuclear binding of the cytosolic receptor complex, reaching a maximum at 3 hours, and leaving little receptor in the $100,000 \mathrm{~g}$ cytosolic supernatant (Fig. 5). Total ER, represented by its nuclear form, decreased by approximately $50 \%$ after a 6 hour exposure of cells to $E_{2}$ (Fig. 5). A maximal value of 2.46 fmoles of ER/ $\mu$ g of DNA was determined for the 139B6 cell line, which was comparable to maximal levels obtained for the samples extracted from MCF-7 cultures (data not shown; approximately 4 fmoles of ER/ $\mu$ g of DNA).

Initial growth characterizations were performed on both ER and vector transfected MCF10A cells. Table 1 summarizes doubling times of cultures after treatment with appropriate media. Overall, the doubling times of the ER-transfected cell line were longer than those of the vector-transfected cell line 
(Table 1). Comparison of the saturation densities for both cell lines in optimal growth media without $\mathrm{E}_{2}$ indicated a slightly higher saturation density for vector-transfected $139-2-8$ cells $\left(480,000 / \mathrm{cm}^{2}\right)$ than for $139 \mathrm{~B} 6$ cells $\left(400,000 / \mathrm{cm}^{2}\right)$. The growth rate of the 139-2-8 cells remained unchanged upon addition of $10^{-8} \mathrm{M} \mathrm{E}_{2}$ to the growth medium (doubling times of 18.1 hours for control growth medium and 18.5 hours upon addition of $\mathrm{E}_{2}$ ). This data is consistent with our results and those previously reported by Soule [9] with the parental cell line MCF10A, where no effect on growth rate was observed upon the addition of $E_{2}$. Addition of $E_{2}$ consistently increased the doubling time of the $139 \mathrm{~B} 6$ cell line by $15 \%$. However, there was no statistical difference in growth rates (Table 1 ).

Withdrawal of EGF from cultures of both 139-2-8 and 139B6 cells resulted in an increased doubling time and lower saturation density, indicating that both cell lines, like the parental MCF10A cells, still require EGF for optimal growth (Table 1). Addition of $E_{2}$ to EGF-depleted media had no effect on growth of these cells (Table 1). Withdrawal of cortisol from 139-2-8 and 139B6 cultures resulted in an increase in doubling times ( 24.7 and 30.6 hours respectively; Table 1), indicating that transfected cultures were still dependent on cortisol for optimal growth. Addition of $\mathrm{E}_{2}$ to cortisol depleted 139B6 cultures resulted in the doubling time increasing from 30.6 to 37.4 hours (Table 1), while no difference in doubling time was observed in the vector transfected 139-2-8 cell line. Under these conditions, the appearance of the 139B6 cells were altered, with cells becoming enlarged and containing many vacuoles (data not shown). This suggests that the addition of $E_{2}$ to 139B6 cells growing in cortisol depleted medium was detrimental.

To determine if the ER expressed in the 139B6 cultures could induce endogenous $E_{2}$ responsive genes in cultures, the effect of $E_{2}$ on levels of $\mathrm{pS} 2$, cathepsin D, PgR and TGF $\alpha$ mRNAs was examined. No expression of the $0.6 \mathrm{~kb}$ pS2 mRNA was observed in any of the MCF10A cultures examined (including the parent MCF10A, 139-2-8 and 139B6 cell lines; data not shown). Both the $2.1 \mathrm{~kb}$ cathep$\sin \mathrm{D}$ and the $4.5 \mathrm{~kb}$ TGF $\alpha \mathrm{mRNAs}$ were detected in all three MCF10A cell lines. However no induction of either mRNA was observed upon addition of $\mathrm{E}_{2}$ (Fig. 6). Interestingly, PgR mRNA was also detected in the parental and transfected MCF10A cells but did not increase in level upon $\mathrm{E}_{2}$ treatment (data not shown). PgR protein, however, was not detected in any of these cultures by ligand binding or Western analysis (data not shown).

The findings that the ER in the 139B6 underwent processing upon exposure to $\mathrm{E}_{2}$ and that $\mathrm{E}_{2}$ could alter growth of 139B 6 cells but not 139-2-8 cells suggested that 139B6 cells are expressing a functional ER. However, since none of the endogenous estrogen responsive genes examined responded to added $E_{2}$ with increased activity, further evidence of receptor function was necessary. For this purpose

Table 1. Doubling times of 139B6 (ER +) and 139-2-8 (ER -) cells

\begin{tabular}{lll}
\hline Treatment & 139 B doubling time $^{\alpha}(\mathrm{n})^{\beta}$ & $1^{\beta}-2-8$ doubling time $^{\alpha}(\mathrm{n})^{\beta}$ \\
\hline Control $^{\mathrm{c}}$ & $21.6 \pm 5.1(3)$ & $18.1 \pm 0.17(2)$ \\
$-\mathrm{HC}^{\mathrm{c}}$ & $30.6 \pm 3.8(2)$ & $24.7(1)$ \\
$-\mathrm{EGF}^{\mathrm{c}}$ & $35.5(1)$ & $32.9(1)$ \\
$-\mathrm{HC},+\mathrm{E}_{2}^{\mathrm{c}}$ & $37.4 \pm 10.4(2)$ & $26.0(1)$ \\
$-\mathrm{EGF},+\mathrm{E}_{2}^{\mathrm{c}}$ & $37.5(1)$ & $30.6(1)$ \\
Control, $+\mathrm{E}_{2}^{\mathrm{c}}$ & $24.8 \pm 4.25(3)$ & $18.5 \pm 0.81(2)$
\end{tabular}

${ }^{a}$ Doubling time was calculated during $\log$ phase growth of cells using the following equation: $(t)[\log 2 / \log (B / A)]=D$, where $t$ is the time of growth in hours; B represents cell number at harvest (or confluency); A represents number of cells seeded; and D represents the doubling time (H. Soule, personal communications). See Materials and methods for experimental design.

${ }^{\mathrm{b}}$ Number in parentheses corresponds to the number of experiments performed. Each experiment consists of three flasks per time point.

' Control media consisted of DMEM/F12 supplemented with 5\% DCC stripped horse serum, cortisol (HC), cholera toxin, insulin, EGF (epidermal growth factor), and antibiotics as described in the Materials and methods. The following abbreviations were used for variations in media: - HC, control media without cortisol; - EGF, control media without $\mathrm{EGF} ;+\mathrm{E}_{2}$ indicated media with $10^{-8} \mathrm{M} \mathrm{E}_{2}$. 
TGF $\alpha$

Cath D

\section{LANE}

1

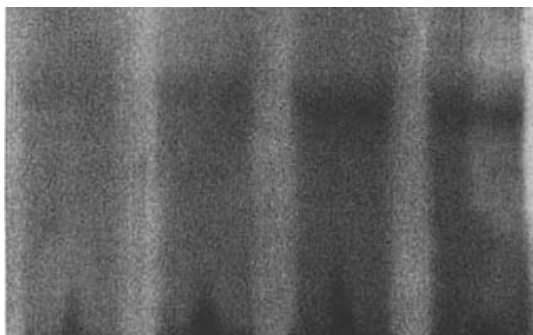

Fig. 6. Effect of $10^{-8} \mathrm{M} \mathrm{E}_{2}$ on levels of cathepsin D and TGF $\alpha$ mRNA in the 139B6 cells. mRNAs from cultures pulsed with ethanol vehicle are shown in lanes 1 and 2 . mRNAs from cells pulsed with $10^{-8} \mathrm{M} \mathrm{E}_{2}$ are shown in lanes 3 and 4 . Cultures were treated with $E_{2}$ for 24 hours and mRNA was harvested as described in the Materials and methods. Northerns were hybridized with ${ }^{35} \mathrm{~S}$ radiolabeled cDNA probes for cathepsin D and TGF $\alpha$. Membranes were subsequently probed with ${ }^{35} \mathrm{~S}$ radiolabeled $36 \mathrm{~B} 4$ cDNA for standardization. Autoradiographs were scanned utilizing a densitometer and quantitated. Blots were then corrected for loading error using densitometric values for $36 \mathrm{~B} 4$ before calculation of fold increase. No change in induction of either mRNA was observed after correction was made.

139B6 and 139-2-8 cells were transfected with the JA12 plasmid, which contains a CAT gene immediately downstream of a regulatory region containing two EREs (one consensus and one mutant) and a minimal thymidine kinase promoter [40]. CAT expression in MCF-7 cells transfected with JA12 can be induced up to 43 fold in the presence of $10^{-11} \mathrm{ME}_{2}$ [40]. Treatment with $\mathrm{E}_{2}$ stimulated transient CAT expression in JA12-transfected 139B6 cells more than 30 fold as compared to cells treated with vehicle alone (ethanol) or to JA12-transfected 139-2-8 cells (Fig. 7). No induction of CAT activity was observed in 139B6 cells treated with the antiestrogen ICI 164,384 .

\section{Discussion}

The recent development of the MCF10 cell lines provides new opportunities to study the progression of breast cancer. These cultures are the only nonmalignant immortalized human breast cell lines developed thus far without chemical or viral intervention. In contrast to breast tumors and breast cancer cell lines which express ER, the MCF10A cell line, like normal breast tissue, does not express significant levels of ER. Our results clearly demonstrate that functional ER can be expressed in MCF10A cells after transfection with a vector containing $\mathrm{ER}_{\mathrm{wt}}$ cDNA under control of a $\beta$-actin promoter. Transfected, but not parental cells, contain the expected $1.9 \mathrm{~kb}$ mRNA. Depending on the clone and the conditions of culture, ER protein may be detected in $10-95 \%$ of cells. This ER is normal by four criteria: 1) the ability of the expressed ER to be recognized by specific monoclonal antibodies, 2) the ability of the expressed ER to bind $E_{2}, 3$ ) the ability of expressed ER to undergo 'processing' (reduction in level of nuclear ER during continuous exposure to $\left.E_{2}[36,42-44]\right)$ and 4) the ability of the expressed ER to activate expression of an ER-responsive CAT reporter gene.

As demonstrated by exposing cells from the ER (+) clone $139 \mathrm{~B} 6$ to $\mathrm{E}_{2}, \mathrm{MCF} 10 \mathrm{~A}$ cells can tolerate expression of ER at the same level as is found in MCF-7 cells with little or no effect on growth or morphology. This contrasts with several reports of detrimental effects or severe inhibition of growth occurring when normal or tumor-derived breast cells overexpressing ER genes are exposed to $\mathrm{E}_{2}[2$, 19, 23]. While we did observe a consistent increase in doubling time of approximately $15 \%$ when $139 \mathrm{~B} 6$ cells were exposed to $\mathrm{E}_{2}$, this response was minimal when compared to growth inhibition described by others $[2,19,23]$. It is likely that this difference in ER expression resulted from the use of a promoter of moderate strength, the $\beta$-actin promoter, rather than strong promoters such as Rous sarcoma virus (RSV), cytomegalovirus (CMV), or metallothionien. The level of ER in 139B6 cells, which had the highest expression of ER in all transfectants isolated in this study, was approximately 9000 receptors per cell (average receptor content of MCF-7 cells is 


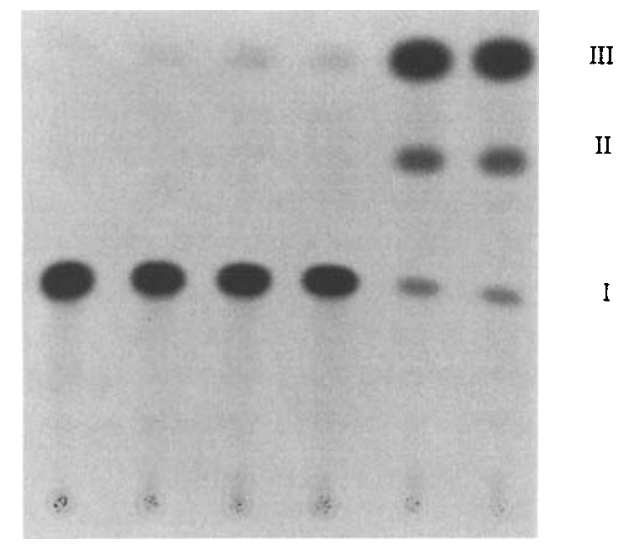

LANE

a

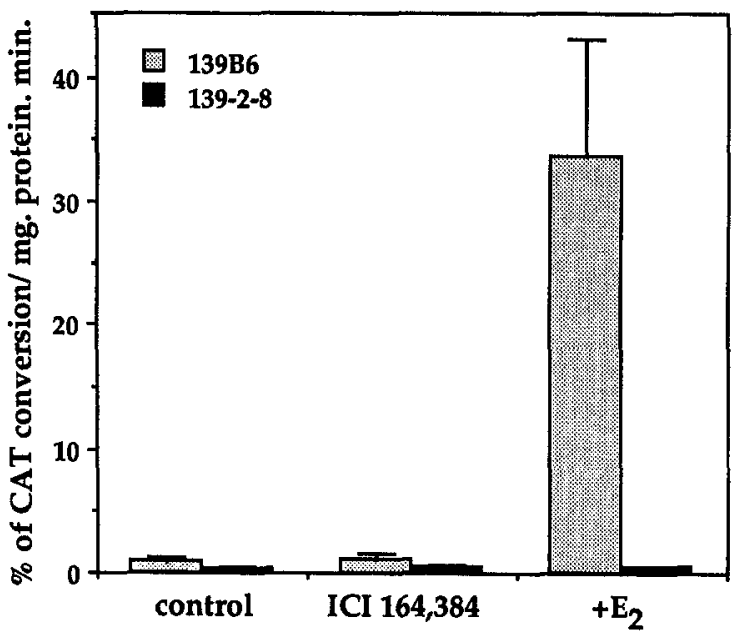

b

Fig. 7. Induction of CAT activity by $\mathrm{E}_{2}$ in JA12 transfected $139 \mathrm{~B} 6$ and 139-2-8 cultures. A) Representative autoradiograph showing CAT activity in 139B6 cultures transiently transfected with the JA12 plasmid. CAT activity in protein lysates extracted from cultures treated with ethanol vehicle (lanes 1 and 2); ICI 164,384 (lanes 3 and 4); and $10^{-8} \mathrm{M} \mathrm{E}_{2}$. The substrate $\left[{ }^{14} \mathrm{C}\right]$ chloramphenicol is designated as I, while the products of the enzyme reaction, 1 - and 3-acetylated $\left[{ }^{14} \mathrm{C}\right]$ chloramphenicol, are indicated by II and III respectively. The acetylated and nonacetylated forms of $\left[{ }^{14} \mathrm{C}\right]$ chloramphenicol were excised and quantified by $\beta$-scintillation counting. B) CAT activity values for the 139B6 cell line represent an average of multiple determinations $(n=6-12)$ with standard deviations depicted by bars. CAT activity values for the 139-2-8 cell line are the average of two experiments. Ranges are depicted by bars. The JA12 plasmid contains a consensus and a mutated ERE upstream of a minimal thymidine kinase promoter fused to the chloramphenicol acetyltransferase (CAT) gene [40]. All details as described in Materials and methods.

10,000-15,000 receptors per cell), while the level of ER in cells transfected with the ER gene under the control of the metallonthionien promoter ranged from 1,000,000-5,000,000 ER per cell [19]. In addition, in 139B6 cells, the regulation of ER gene expression more closely mimics regulation by the endogenous ER promoter in MCF-7 cells, i.e. downregulation as the cells enter stationary phase [44]. Although several groups have reported constitutive expression of $\beta$-actin $[27,45,46]$, in a number of cell types, $\beta$-actin transcription is cell-cycle dependent $[47,48]$. Thus, $139 \mathrm{~B} 6$ cell growth may be less affected by the presence of $E_{2}$ in the medium either because the number of ER in the cell did not reach the level where transcriptional interference or squelching occurs [19] or because ER expression ceases when the cells enter $G_{0}$.

Transfection and selection had no effect on the growth factor and hormone dependence of 139B6 and 139-2-8 cells when compared to that of the parent line, MCF10A [9]. Removal of either EGF or cortisol from the growth medium still caused an in- crease in the doubling time of 139B6 and 139-2-8 cells (Table 1). This indicates that both hormones are necessary for optimal growth of transfected and parental MCF10A cells. However, while $\mathrm{E}_{2}$ had no effect on the growth or morphology of 139B6 cells growing in the absence of EGF, it was able to modulate their growth rate when cells were cultured in the absence of cortisol. As MCF10 cultures appear to be more dependent on EGF for optimal growth than cortisol, the detrimental effect of removing EGF from the medium may mask the modest decrease in growth rate upon addition of $\mathrm{E}_{2}$.

Finally, our findings that $\mathrm{E}_{2}$ can induce a marked increase in transient CAT expression from an $\mathrm{E}_{2}$ responsive CAT reporter gene construct indicates that the ER produced in 139B6 cells is fully capable of interacting with the transcriptional machinery of the cell. Nevertheless, none of the endogenous $\mathrm{E}_{2}$ responsive genes studied ( $\mathrm{pS} 2$, cathepsin D, PgR, or TGF- $\alpha$ ) were stimulated when 139B6 cells were treated with $\mathrm{E}_{2}$. Zajchowski and Sager have previously reported that $\mathrm{pS} 2$ transcription can be activa- 
ted in ER(+) ER-transfected tumor derived cell lines but not in ER(+) ER-transfected cell lines derived by treating normal human mammary cells with benzo[a]pyrene (184B5: [24]). Further studies by this group involving somatic hybrids of the ERtransfected immortalized normal cell line and the $\mathrm{ER}+/ \mathrm{pS} 2+\mathrm{MCF}-7$ breast cancer cell line resulted in the abolishment of pS2 expression in these hybrid cells [49]. This phenomenon was also observed in somatic hybrids of the parental immortalized cell line and MCF-7 [49]. Moreover, these hybrid cells are suppressed in their tumorigenic ability, displaying characteristics similar to the 'normal' parental cell line. This suggests the existence of a tumor suppressor gene product in normal epithelial cells which is not active in tumor cells [24, 49]. If a protein of this nature exists in normal breast cells, pS2 mRNA expression would not be expected in MCF10A cells. Likewise, based on the results of Zajchowski and Sager, pS2 mRNA expression would not be expected in ER-transfected MCF10A cell.

In contrast to results obtained from other groups, however, no detectable induction of cathepsin D, PgR or TGF $\alpha$ mRNAs by $E_{2}$ was observed in 139B6 cultures, indicating that additional factors may play a role determining the response of these genes [20, $49]$. In the case of cathepsin D, failure to see an increase in mRNA levels in response to $E_{2}$ may simply indicate that transcription of the gene has already been fully induced by other growth factors present in media. Transcription of the cathepsin D gene is regulated by several growth factors including EGF and insulin, both of which are present in MCF10A growth medium [50]. No attempts were made to examine the effect of $E_{2}$ on cathepsin D mRNA levels in cells grown in media which did not contain added growth factors because cell viability is dramatically reduced by their removal. However, this hypothesis is supported by earlier studies on $\mathrm{E}_{2}$ induction of cathepsin D mRNA expression in MCF-7 cells. These studies showed that natural variations in hormone and growth factor content of sera often resulted in high levels of cathepsin D mRNA in cells grown in the absence of $\mathrm{E}_{2}$ and reduced the magnitude of subsequent response to $\mathrm{E}_{2}$ addition [32].

Still a third factor may play a role. Although the level of ER falls rapidly after $\mathrm{MCF}-7$ cells reach confluency, induction of accumulation of mRNAs from a number of $E_{2}$-responsive genes, including $\mathrm{pS} 2, \mathrm{PgR}$, and TGF $\alpha$, is more efficient when $\mathrm{E}_{2}$ is added to cultures as they enter confluency than when they are in the logarithmic stage of growth [31, $32,35,51]$. In the studies presented here, all experiments were performed with subconfluent cultures since ER was diminished in confluent 139B6 cells. Thus, it is possible that ER expression was turned off too early to allow optimal expression of endogenous $\mathrm{E}_{2}$-responsive genes in the 139B6 cells.

Although it is clear that regulation of ER transcription by the $\beta$-actin promoter is likely to differ in several aspects from regulation by the endogenous ER promoter, the results presented here demonstrate that expression of functional ER in immortalized breast epithelial cells is not sufficient to cause gross morphological and growth changes characteristic of breast tumor cells. Since MCF10A cells were derived from a patient with fibrocystic disease and are not tumorigenic in nude-beige mice [9], our results also suggest that if ER expression is to provide a growth advantage during the early stages of progression of proliferative breast disease, the cells must first have undergone some additional changes that allow their growth to be stimulated by $\mathrm{E}_{2}$ rather than be unchanged or inhibited. Thus, the availability of ER(+) MCF10A cells should provide an excellent system for determining what additional changes lead to increased growth potential in response to $E_{2}$ and for exploring how $E_{2}$ itself may help to bring about changes leading to progression of preneoplastic breast epithelial cells.

\section{Acknowledgements}

The authors gratefully acknowledge Dr. Kenneth Pienta and Dr. Herb Soule for their critical reading of the manuscript. Also special thanks to Lisa Polin and Mikehl Hafner for their technical advice and assistance. These investigations were supported in part by NIH Grant CA44771 and the Lloyd and Marilyn Smith Fund (J.C.). 


\section{References}

1. Beatson GT: On the treatment of inoperable cases of carcinoma of the mamma: suggestions for a new method of treatment with illustrative cases. Lancet ii: 104-107, 1896

2. Zajchowski DA, Sager R, Webster L: Estrogen inhibits the growth of estrogen receptor-negative, but not estrogen receptor-positive, human mammary epithelial cells expressing a recombinant receptor. Cancer Res 53: 5004-5011, 1993

3. Brooks SC, Pauley R: Breast Cancer Biology. In: Dulbecco $R$ (ed) Encyclopedia of Human Biology, vol 2. Academic Press Inc, San Diego, 1991, pp 53-65

4. Peterson OW, Hoyer PE, VanDeurs B: Frequence and distribution of estrogen receptor-positive cells in normal, nonlactating human breast tissue. Cancer Res 47: 5748-5751, 1987

5. Khan SA, Rogers MAM, Obando JA, Tamsen A: Estrogen receptor expression of benign breast epithelium and its association with breast cancer. Cancer Res 54: 993-997, 1994

6. Vogelstein B, Kinzler KW: The multistep nature of cancer. Trends in Genetics 9: 138-141, 1993

7. Fearon ER, Vogelstein B: A genetic model for colorectal tumorigenesis. Cell 61: 759-767, 1990

8. Bartek J, Bartkova J, Kyprianou N, Lalani E-N, Staskova Z, Shearer M, Chang S, Taylor-Papadimitriou J: Efficient immortalization of luminal epithelial cells from human mammary gland by introduction of Simian virus 40 large tumor antigen with a recombinant retrovirus. Proc Natl Acad Sci USA 88: 3520-3524, 1991

9. Soule HD, Maloney TM, Wolman SR, Peterson WD Jr, Brenz R, McGrath CM, Russo J, Pauley RJ, Jones RF, Brooks SC: Isolation and characterization of a spontaneously immortalized human breast epithelial cell line, MCF10. Cancer Res 50: 6075-6086, 1990

10. Briand P, Peterson OW, van Deurs B: A new diploid nontumorigenic human breast epithelial cell line isolated and propagated in chemically defined media. In vitro Cell Dev Biol 23: 181-188, 1987

11. Caron de Fromentel C, Nardeux PC, Soressi T, Lavialle C, Estrade S, Carloni G, Chandrasekaran K, Carsingena R: Epithelial HBL-100 cell line derived from milk of an apparently healthy woman harbors SV40 genetic information. Exp Cell Res 16: 83-94, 1985

12. Stampfer MR, Bartley JC: Induction of transformation and continuous cell lines from normal human mammary epithelial cells after exposure to benzo[a]pyrene. Proc Natl Acad Sci USA 82: 2394-2398, 1985

13. Chang SE, Keen J, Lane EB, Taylor-Papadimitriou J: Establishment and characterization of SV40-transformed breast epithelial cell lines. Cancer Res 42: 2040-2053, 1982

14. Gaffney EV: A cell line (HBL-100) established from breast milk. Cell Tissue Res 227: 563-568, 1982

15. Hackett AJ, Smith HS, Springer EL, Owens RB, Nelson Rees NA, Riggs JL, Gardner MB: Two syngeneic cell lines from human breast tissue: the aneuploid mammary epithe- lial (Hs578T) and the diploid myoepithelial (Hs578Bst) cell lines. J Natl Cancer Inst 58: 1795-1806, 1977

16. Berry M, Metzger D, Chambon P: Role of the two activation domains of the oestrogen receptor in the cell-type and promoter-context dependent agonistic activity of the anti-oestrogen 4-hydroxytamoxifen. EMBO J 9: 2811-2818, 1990

17. Metzger D, White JH, Chambon P: The human estrogen receptor functions in yeast. Nature 334: 31-36, 1988

18. Greene GL, Gilna P, Waterfield M, Baker A, Hort Y, Shine $J$ : Sequence and expression of human estrogen receptor complementary DNA. Science 231: 1150-1154, 1986

19. Kushner PJ, Hort E, Shine J, Baxter JD, Greene GL: Construction of cell lines that express high levels of the human estrogen receptor and are killed by estrogens. Mol Endocrinol 4: 1465-1473, 1990

20. Touitou I, Mathieu M, Rochefort H: Stable transfection of the estrogen receptor cDNA into HeLa cells induces estrogen responsiveness of endogenous cathepsin D gene but not of cell growth. Biochem Biophys Res Commun 169:109-115, 1990

21. Sadovsky Y, Kushner PJ, Roberts JM, Riemer RK: Restoration of estrogen-dependent progesterone receptor expression in a uterine myocyte cell line. Endocrinology 132: 1609 1613,1993

22. Migliaccio S, Davis VL, Gibson MK, Gray TK, Korach KS: Estrogens modulate the responsiveness of osteoblast-like cells (ROS 17/2.8) stably transfected with estrogen receptor. Endocrinology 130: 2617-2624, 1992

23. Jiang SY, Jordan VC: Growth regulation of estrogen receptor-negative breast cancer cells transfected with complementary DNAs for estrogen receptor. J Natl Cancer Inst 8: 580-591, 1992

24. Zajchowski DA, Sager R: Induction of estrogen-regulated genes differs in immortal and tumorigenic human mammary epithelial cells expressing a recombinant estrogen receptor. Mol Endocrinol 5: 1613-1623, 1991

25. Wiese TE, Kral LG, Dennis KE, Butler WB, Brooks SC: Optimization of estrogen growth response in MCF-7 cells. In vitro Cell Dev Biol 28A: 595-602, 1992

26. Tora L, Mullick A, Metzger D, Ponglikitmongkol M, Park I, Chambon P: The cloned human oestrogen receptor contains a mutation which alters its hormone binding properties. EMBO J 8: 1981-1986, 1989

27. Gunning P, Leavitt J, Muscat G, Ng S-Y, Kedes L: A human beta-actin expression vector system directs high-level accumulation of antisense transcripts. Proc Natl Acad Sci USA 84: 4831-4835, 1987

28. Green $S$, Issemann I, Sheer E: A versatile in vivo and in vitro eukaryotic expression vector for protein engineering. $\mathrm{Nu}$ cleic Acids Res 16: 369, 1988

29. Sambrook J, Fritsch EF, Maniatis T: Molecular Cloning: A Laboratory Manual. 2nd edition, Cold Spring Harbor Laboratory Press, 1989

30. Ausubel FM, Brent R, Kingston RE, More DM, Smith JA, Seidman JG, Struhl K (eds) Current Protocols in Molecular 
Biology. Greene Publishing Associates and Wiley Interscience, New York, 1987

31. Davis MD, Butler WB, Brooks SC: Induction of tissue plasminogen activator mRNA and activity by structurally altered estrogens. J Steroid Biochem Mol Biol 52: 421-430, 1995

32. Pilat MJ, Hafner MS, Kral LG, Brooks SC: Differential induction of pS2 and cathepsin D mRNAs by structurally altered estrogens. Biochemistry 32: 7009-7015, 1993

33. Davies IJ, Naftolin F, Ryan KJ, Fishman J, Siu J: The affinity of catechol estrogens for estrogen receptors in the pituitary and anterior hypothalamus of the rat. Endocrinology 97: 554-557, 1975

34. Scatchard G: The attraction of proteins for small molecules and ions. Ann NY Acad Sci 51: 660-672, 1949

35. Vander Kuur JA, Wiese T, Brooks SC: Influence of estrogen structure on nuclear binding and progesterone receptor induction by the receptor complex. Biochemistry 32: 70027008,1993

36. Kral L, Doherty LM, Brooks SC: Quantitative determination of nuclear estrogen receptors by an enzyme immunoassay: applications and caveats. J Steroid Biochem 31: 459466,1988

37. Burton KA: A study of conditions and mechanism of diphenylamine reaction for the colormetric estimation of deoxyribonucleic acid. Biochem J 62: 315-322, 1956

38. Butler WB: Preparing nuclei from cells in monolayer cultures suitable for counting and for following synchronized cells through the cell cycle. Anal Biochem 141: 70-73, 1984

39. Brash DE, Reddel RR, Quanrud M, Yang K, Farrell MP, Harris CC: Strontium phosphate transfection of human cells in primary culture: stable expression of the Simian virus 40 large T-antigen gene in primary human bronchial epithelial cells. Mol Cell Biol 7: 2031-2034, 1987

40. VanderKuur JA, Hafner MS, Christman JK, Brooks SC: Effects of estradiol-17 $\beta$ analogues on activation of estrogen responsive element regulated chloramphenicol acetyltransferase expression. Biochemistry 32: 7016-7021, 1993

41. Gorman CM, Moffat LF, Howard BH: Recombinant genomes which express chloramphenicol acetyltransferase in mammalian cells. Mol Cell Biol 2: 1044-1049, 1982

42. Gyling M, Leclercq G: Estrogen and antiestrogen interac- tion with estrogen receptor of MCF7 cells - relationship between processing and estrogenicity. J Steroid Biochem 29: 1-8, 1988

43. Saceda M, Lippman ME, Chambon P, Lindsey RL, Ponglikitmongkol M, Puente M, Martin MB: Regulation of the estrogen receptor in MCF-7 cells by estradiol. Mol Endocrinol 2: 1157-1162, 1988

44. Brooks SC, Hansen ER, Saunders DE, Battelli MG, Shafie SM: Effect of growth on the estrogen receptor levels in MCF-7 cells. Cancer Res 44: 3724-3729, 1984

44. Horwitz KB, McGuire WL: Estrogen control of progesterone receptor in human breast cancer: correlation with nuclear processing of estrogen receptor. J Biol Chem 253: 2223 2228,1978

45. Danilition SL, Frederickson RM, Taylor CY, Miyamoto NG: Transcription factor binding and spacing constraints in the human beta-actin proximal promoter. Nucleic Acids Res 19: 6913-6922, 1991

46. Morishita H, Nakamura N, Yamakawa T, Ogino H, Kanamori T, Nobuhara M, Namba M: Stable expression of human tissue-type plasminogen activator regulated by beta-actin promoter in three human cell lines: HeLa, WI-38 VA13, and KMS-5. Biochim Biophys Acta 1090: 216-222, 1991

47. Rhode PR, Gorski J: Growth and cell cycle regulation of mRNA levels in GH3 cells. Mol Cell Endocrinol 82: 11-22, 1991

48. Greenberg ME, Ziff EB: Stimulation of $3 T 3$ cells induces transcription of the c-fos proto-oncogene. Nature 311: 433 438,1984

49. Zajchowski DA, Band V, Trask DK, Kling D, Connolly JL, Sager R: Suppression of tumor-forming ability and related traits in MCF-7 human breast cancer cells by fusion with immortal mammary epithelial cells. Proc Natl Acad Sci USA 87: 2314-2319, 1990

50. Cavailles V, Garcia M, Rochefort H: Regulation of the cathepsin D and $\mathrm{pS} 2$ gene expression by growth factors in MCF-7 human breast cancer cells. Mol Endocrinol 3: 552558,1989

51. May FEB, Westley BR: Cloning of estrogen-regulated messenger RNA sequences from human breast cancer cells. Cancer Res 46: 6034-6040, 1986 